\title{
Primary dysmenorrhea magnitude, associated risk factors, and its effect on academic performance: evidence from female university students in Ethiopia
}

This article was published in the following Dove Press journal:

International Journal of Women's Health

19 September 2016

Number of times this article has been viewed

\author{
Solomon Hailemeskel' \\ Asrate Demissie ${ }^{2}$ \\ Nigussie Assefa ${ }^{3}$ \\ 'Department of Midwifery, College \\ of Health Science, Institute of \\ Medicine and Health Science, Debre \\ Berhan University, Debre Berhan, \\ Ethiopia; ${ }^{2}$ Department of Nursing \\ and Midwifery, School of Allied \\ Health Science, College of Health \\ Sciences, Addis Ababa University, \\ Addis Ababa, Ethiopia; ${ }^{3}$ Department \\ of Reproductive Health and Health \\ Service Management, School of Public \\ Health, College of Health Sciences, \\ Addis Ababa University, Addis Ababa, \\ Ethiopia
}

Background: Primary dysmenorrhea (PD) is the most common gynecologic compliant among adolescent females. There is a wide variation in the estimate of PD, which ranges from $50 \%$ to $90 \%$, and the disorder is the most common cause of work and school absenteeism in adolescent females.

Objective: To assess the prevalence and associated risk factors of PD among female university students and understand its effects on students' academic performance.

Methods: A cross-sectional study was employed in 440 research participants. A multistage stratified sampling technique was employed to select the study units. Structured and pretested self-administered questionnaires were used and weight and height measurements were conducted. The severity of dysmenorrheal pain was assessed by using a verbal multidimensional scoring system and visual analog scale. The data were double entered in Epi Info version 3.1 and analyzed using SPSS version 17. Descriptive statistics, chi-square test, and logistic regression analysis were performed.

Results: A total of 440 students participated in this study. The prevalence of PD was $368(85.4 \%)$. Of these, 123 (28.5\%) had mild, 164 (38.1\%) moderate, and 81 (18.8\%) severe primary dysmenorrheal pain. Among students with PD, $88.3 \%$ reported that PD had a negative effect on their academic performance. Of these, $80 \%$ reported school absence, $66.8 \%$ reported loss of class concentration, $56.3 \%$ reported class absence, $47.4 \%$ reported loss of class participation, $37.8 \%$ reported limited sport participation, $31.7 \%$ reported limitation in going out with friends, and $21 \%$ reported inability to do homework. Based on the multivariate logistic regression, PD was statistically significant with those who had lower monthly stipends, a history of attempt to lose weight, a history of depression or anxiety, disruption of social network of family, friends or people they love, who consumed more than four glasses of tea per day, who drunk one or more Coca-Cola or Pepsi per day, in nullipara, and students with a family history of dysmenorrhea. Conclusion: PD is more prevalent among female students attending university. It has a significant negative impact on students' academic performance. Thus, it needs medical attention. There are various identified associated risk factors and considering them in the management of the disorder is fundamental. It is also wise to recommend future studies to better identify risk factors for PD and lighten its effect on students' academic performance at a larger scale in the country.

Keywords: academic performance, risk factors, dysmenorrhea, Ethiopia, adolescents, young, higher institution

\section{Introduction}

Primary dysmenorrhea (PD) is pain during menstrual bleeding without organ pathological abnormalities. ${ }^{1}$ It usually begins during adolescence. ${ }^{2,3}$ Affected females
PO Box 17193, Addis Ababa, Ethiopia

Tel +25l 912142509

Email nigussie19@gmail.com 
experience sharp, intermittent spasm of pain usually concentrated on the supra pubic area and which may radiate to the back of the legs. Pain usually develops within hours of the start of the menstruation and peaks as the flow becomes heaviest during the first day or two of the cycle. ${ }^{4}$

$\mathrm{PD}$ is a key women's health burden ${ }^{5}$ and is also one of the public problems in the world. ${ }^{6}$ An estimated 140 million hours are lost annually from school or work because of dysmenorrhea; ${ }^{7}$ for example, in the US, $\sim 600$ million working hours are lost annually as a result of PD. ${ }^{8}$ PD is the leading cause of work or school absenteeism in women ${ }^{5}$ and a leading cause of recurrent short-term school absenteeism among adolescent girls. ${ }^{9}$

Several research findings showed that the proportions of PD and/or dysmenorrhea in young females are higher. In studies from three medical colleges of India, ${ }^{10}$ Turkish University, ${ }^{6}$ Mexican University, ${ }^{11}$ and Thailand, ${ }^{12}$ students reported that the prevalence rate of dysmenorrhea as $73.83 \%$, $55.5 \%, 64 \%$, and $84.9 \%$, respectively. A study done among Hispanic female adolescents found that 3 months prior to the study $85 \%$ of the adolescents reported experiencing dysmenorrhea. ${ }^{13}$ A study done among 356 Naples professional institute adolescents ${ }^{14}$ and Nigeria college students in the urban area of Ile-Ife, Osun, ${ }^{15}$ found the prevalence of PD as $82.30 \%$ and $62.5 \%$, respectively. Another study done in Dabat and Kola Diba showed $72 \%$ prevalence of dysmenorrhea in secondary school students. ${ }^{16}$

PD is believed to be associated with many factors, including behavioral and psychological aspects. Age $<20$ years, nulliparity, heavy menstrual flow, smoking, high socioeconomic status, attempts to lose weight, physical activity, disruption of social networks, depression, and anxiety are risk factors of dysmenorrhea. ${ }^{7}$ A long and heavy menstrual flow is related to an increase in the severity of dysmenorrhea. Concerning dietary habits of students, it was noted that a higher consumption of fish, eggs, fruit, and a lower consumption of wine was correlated with a lower frequency of dysmenorrhea. ${ }^{14}$ According to a study done in Dumlupinar University, coffee consumption, menstrual bleeding with duration $\geq 7$ days, and positive family history of dysmenorrhea were reported as important risk factors for dysmenorrhea. ${ }^{17}$ Another study indicated that smoking status ${ }^{18,19}$ and depressive symptoms/anxiety ${ }^{18,20}$ were related to menstrual symptoms and the impact of depressive symptoms/anxiety on menstrual symptoms was strongly associated among nonsmokers as well. ${ }^{18}$ Other studies also showed that risk factors related to dysmenorrhea are heavy menstrual blood flow (prolonged or aberrant menstrual blood flow), ${ }^{21-24}$ a younger age (age $<20$ years), low body mass index (BMI), nulliparity, smoking, early menarche, premenstrual syndrome, clinically suspected pelvic inflammatory disease, somatization, psychological disturbance, disruption of social relations with family or friends, and poor mental health, such as depression and anxiety..$^{21,23,24}$

Dysmenorrhea adversely affects the personal life of adolescents and limits their social and academic performance. A study by Mexican university students found that dysmenorrhea affects $65 \%$ of students' daily activities. ${ }^{25}$ Based on this study, the characteristics of menstrual factors that limit students' daily activities were cramping pain in the lower abdomen (93\%), swollen abdomen (67\%), irritability (50\%), depression (48\%), painful or tender breasts (45\%), backache (43\%), gastrointestinal disturbances (26\%), headache (24\%), and swelling legs (19\%). ${ }^{25}$ In addition to this, menstrual pain and distress can cause disability (loss of function and activity) and handicap (altered social roles). ${ }^{1,2}$

Affecting female students' academic performance, ${ }^{12,13,26}$ absenteeism from school ${ }^{6,8,10,12,13,15,17,22,27-29}$ and loss of work days ${ }^{8,22,27-29}$ are common in a woman with dysmenorrhea or $\mathrm{PD}$, which result in significant economic consequences.

This research gives insights on PD-associated risk factors, the severity of this disorder among groups of female students, and its effect on their academic performance. Besides, it also opens the window for further large scale studies.

\section{Materials and methods}

\section{Study design and population}

A cross-sectional study design was used to conduct the research in Debre Berhan University in 2012. The university is one of the public universities in Ethiopia and has been enrolling students from all regions of the country. The population of the study was all regular female students who were randomly selected from colleges and schools from first year to fourth year batches. A total of 440 female students were involved in the study.

\section{Sampling procedure, data collection tools, and procedure}

Participants were selected from all female students of the university using multistage sampling technique. Probability proportionate sampling method was also applied to allocate the sample size according to the strata. The strata are categorized based on the batch/academic year of students. In order to select colleges and schools, simple random sampling techniques were applied.

Pretest was administered to 22 students, which accounts for $5 \%$. Regarding their background, all of them were 
selected from similar socioeconomic status. These students were not involved in the main study.

Structured self-administered questionnaires were used. The questionnaire items were adapted from previous studies. ${ }^{13,30,31}$ Some terms were given operational definitions. For instance, class absence was defined as when students miss individual classes because of PD during the last month prior to the data collection and school absence was to mean when students miss a school day due to primary dysmenorrheal pain during the last month prior to the data collection. The tool includes sociodemographic characteristics, student's psychosocial factor and family planning history, dysmenorrheal status, menstrual characteristics, activities affected by PD, behavioral factors, and PD effect on student's academic performance. The questionnaires also included visual analogue scale questions and multidimensional scoring system to assess the severity of PD. ${ }^{30}$ The questionnaires were translated to local languages.

Training for data collectors and supervisors was given in understanding the objective of the survey, methods of data collection, and ways of approaching the respondents. The supervisor checked the activities of each data collector and all the filled questionnaires for its completion, clarity, and proper identification of the respondents. Then, the questionnaires were checked again for the completion by the principal investigator.

\section{Data analysis}

The data were checked manually for completeness during their collection, and then coded and entered into Epi Info version 3.1 statistical software (Centers for Disease Control and Prevention, Atlanta, GA, USA). Then, it was analyzed by SPSS version 17 software application (SPSS Inc., Chicago, IL, USA). Inferential analysis was done by logistic regression.

\section{Ethical consideration}

The ethical approval for this study was granted by the Institutional Review Board of the College of Health Sciences, Addis Ababa University. All participants provided verbal consent. Written consent was not required, as confidentiality and anonymity were strictly maintained, and the study could cause no harm to the study participants.

\section{Results}

\section{Sociodemographic characteristics} and respondents' BMI

In all, $98 \%$ of the respondents were involved in the study. The mean ages of respondents were $20.57 \pm 1.36$ (standard deviation). Christianity was the major (89.56\%) religion of the respondents. The majority $(90.7 \%)$ of the respondents were single, and $28.1 \%$ had an average monthly income $<7$ USD, $50.1 \%$ received $7-17$ USD, and the remainder received $>17$ USD. Regarding their family income, the majority (50.1\%) earned between 88.25 and 176.47 USD (Table 1).

The majority of respondents' (347 [80.5\%]) BMI value rested on the normal range $\left(18.00-24.99 \mathrm{~kg} / \mathrm{m}^{2}\right)$, whereas the rest $(49[11.4 \%])$ were malnourished $\left(<18.00 \mathrm{~kg} / \mathrm{m}^{2}\right)$ and 35 (8.1\%) were overweight (25.00-29.99 kg/m²) (Figure 1).

\section{Prevalence of PD and its effect on students' academic performance}

The prevalence of PD accounted for $85.4 \%$ and $88.3 \%$ of the respondents with $\mathrm{PD}$ reported that the disorder interferes with their academic performance. The most commonly reported effect of menstrual pain on students' academic performance was: school absence (260 [80\%]), loss of class concentration (217 [66.8\%]), class absence (183 [56.3\%]), loss of class participation (154 [47.4\%]), limited sport participation (123 [37.8\%]), limited going out with friends (103 [31.7\%]), inability to do homework (68 [21\%]), and reduced test taking skill (50 [15.4\%]) (Table 2).

Table I Sociodemographic characteristics

\begin{tabular}{|c|c|c|c|}
\hline Variable & Category & $\begin{array}{l}\text { Participants } \\
\text { (n) }\end{array}$ & $\begin{array}{l}\text { Participants } \\
\text { (\%) }\end{array}$ \\
\hline \multirow[t]{3}{*}{ Age } & $\leq 20$ years & 220 & 51.0 \\
\hline & $2 \mathrm{I}-22$ years & 180 & 41.8 \\
\hline & $>23$ years & 31 & 7.2 \\
\hline \multirow[t]{2}{*}{ Religion } & Christian & 386 & 89.6 \\
\hline & Muslim & 45 & 10.4 \\
\hline \multirow[t]{5}{*}{ Ethnicity } & Amhara & 316 & 73.3 \\
\hline & Oromo & 41 & 9.5 \\
\hline & Tigrie & 40 & 9.3 \\
\hline & Guragie & 19 & 4.4 \\
\hline & Others & 15 & 3.5 \\
\hline \multirow[t]{2}{*}{ Marital status } & Single & 391 & 90.7 \\
\hline & Ever married & 40 & 9.3 \\
\hline \multirow[t]{4}{*}{ Educational level } & First year & 115 & 26.7 \\
\hline & Second year & 136 & 31.6 \\
\hline & Third year & 160 & 37.1 \\
\hline & Fourth year & 20 & 4.6 \\
\hline \multirow[t]{3}{*}{ Monthly income } & $<150$ ETB & 121 & 28.1 \\
\hline & I50-300 ETB & 216 & 50.1 \\
\hline & $>300$ ETB & 94 & 21.8 \\
\hline \multirow[t]{3}{*}{ Family income } & $<\mathrm{I}, 500 \mathrm{ETB}$ & 121 & 28.1 \\
\hline & I,500-3,000 ETB & 216 & 50.1 \\
\hline & $>3,000$ ETB & 94 & 21.8 \\
\hline \multirow[t]{2}{*}{ Parity } & Nullipara & 372 & 86.3 \\
\hline & Multipara & 59 & 13.7 \\
\hline
\end{tabular}

Note: I ETB is equivalent to 0.06 USD.

Abbreviation: ETB, Ethiopian Birr. 


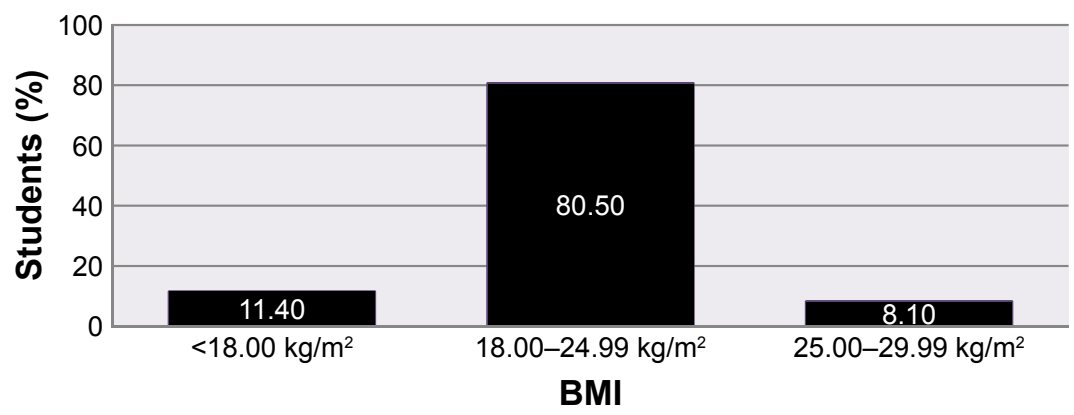

Figure I BMI of students.

Abbreviation: BMI, body mass index.

\section{PD pain characterization}

According to the verbal multidimensional scoring system and visual analog scale for assessment of PD pain, out of 368 (85.4\%) students who had menstrual pain, 123 (28.5\%) students' menstruation was painful but seldom inhibits normal activity and analgesics are seldom required (mild pain). The

Table 2 Prevalence and effect of primary dysmenorrhea on academic performance

\begin{tabular}{|c|c|c|c|}
\hline Variable & Category & $\begin{array}{l}\text { Participants } \\
\text { (n) }\end{array}$ & $\begin{array}{l}\text { Participants } \\
(\%)\end{array}$ \\
\hline Menstruation & Yes & 368 & 85.4 \\
\hline associated with pain & No & 63 & 14.6 \\
\hline Menstrual problems & Yes & 325 & 88.3 \\
\hline interfere with & No & 43 & 11.7 \\
\hline \multicolumn{4}{|c|}{$\begin{array}{l}\text { school performance } \\
\text { Effects of menstrual School absence }\end{array}$} \\
\hline pain on school & Yes & 260 & 80.0 \\
\hline \multirow{28}{*}{ performance } & No & 65 & 20.0 \\
\hline & Class absence & & \\
\hline & Yes & 183 & 56.3 \\
\hline & No & 142 & 43.7 \\
\hline & Inability to do & & \\
\hline & homework & & \\
\hline & Yes & 68 & 21.0 \\
\hline & No & 257 & 79.0 \\
\hline & Loss of class & & \\
\hline & participation & & \\
\hline & Yes & 154 & 47.4 \\
\hline & No & $17 \mid$ & 52.6 \\
\hline & Loss of class & & \\
\hline & concentration & & \\
\hline & Yes & 217 & 66.8 \\
\hline & No & 108 & 33.2 \\
\hline & Reduced test & & \\
\hline & taking skill & & \\
\hline & Yes & 50 & 15.4 \\
\hline & No & 275 & 84.6 \\
\hline & Limited sport & & \\
\hline & participation & & \\
\hline & Yes & 123 & 37.8 \\
\hline & No & 202 & 62.2 \\
\hline & Limitation in going & & \\
\hline & out with friends & & \\
\hline & Yes & 103 & 31.7 \\
\hline & No & 222 & 68.3 \\
\hline
\end{tabular}

majority of students' (164 [38.1\%]) daily activity was affected; analgesics were required and gave sufficient relief so that absence from school was unusual (moderate pain). Additionally, in 81 (18.8\%) of students, daily activity was clearly inhibited by PD, the effect of analgesics to give relief of the pain was insignificant, and they experienced vegetative symptoms such as headache, fatigue, vomiting, and diarrhea (severe pain).

\section{Logistic regression analysis of significant variables related to $\mathrm{PD}$ \\ Students' sociodemographic characteristics versus PD}

Table 3 shows the results of the multivariate analysis using significant bivariate variables for student's sociodemographic characteristics. The analysis showed that students in the third and fourth years of university had a lower risk of PD. The risk of PD was 0.046 times less in the second year (adjusted odds ratio $[\mathrm{AOR}]=0.046,95 \%$ confidence interval $[\mathrm{CI}]$ [0.014-0.288], $P \leq 0.001), 1.08$ times higher in first year, though it was not statistically significant when adjusted for possible confounders (crude odds ratio $=2.242,95 \% \mathrm{CI}$ [1.141-4.406], $P=0.019$ ) and (crude odds ratio $=1.080,95 \%$ CI [0.204-5.721], $P=0.019)$. The risk of PD was 6.671 times higher in students whose monthly income was $<150$ ETB compared with students whose monthly income was above 300 ETB $($ AOR $=6.671,95 \%$ CI [1.427-31.180], $P=0.016)$.

The risk of PD in students who had a history of attempt to lose weight was approximately six times higher than students with no prior history of attempt to lose weight $(\mathrm{AOR}=6.085$, 95\% CI [1.998-18.529], $P=0.001)$. Other risk factors for PD were $\sim 14$ times higher risk in students who had a previous history of depression or anxiety compared with those who had no prior history of depression or anxiety $(\mathrm{AOR}=13.607$, 95\% CI [4.542-40.767], $P \leq 0.001$ ); an approximately three times higher risk in students who had a previous history of disruption of social network, such as with family, friends, or people they love compared with students who had no prior 
Table 3 Student's sociodemographic variables versus primary dysmenorrhea

\begin{tabular}{|c|c|c|c|c|}
\hline \multirow[t]{2}{*}{ Variable } & \multicolumn{2}{|c|}{ Primary dysmenorrhea, n (\%) } & \multirow[t]{2}{*}{ Adjusted OR (95\% Cl) } & \multirow[t]{2}{*}{$P$-value } \\
\hline & Yes $(n=368)$ & No $(n=63)$ & & \\
\hline \multicolumn{5}{|l|}{ Educational level } \\
\hline Ist year & $102(27.7)$ & $13(20.6)$ & $\mathrm{I} .080(0.204-5.72 \mathrm{I})$ & 0.927 \\
\hline 2nd year & $126(34.2)$ & $10(15.9)$ & $0.064(0.014-0.288)^{*}$ & $<0.001$ \\
\hline $3 r d$ and 4th year & $140(38.0)$ & $40(63.5)$ & 1 & \\
\hline \multicolumn{5}{|c|}{ Students' monthly income** } \\
\hline$<$ I50 ETB & $103(28.0)$ & $7(11.1)$ & $6.67 \mid(1.427-31.180)^{*}$ & 0.016 \\
\hline I50-200 ETB & $95(25.8)$ & $20(31.7)$ & $0.572(0.162-2.025)$ & 0.386 \\
\hline $20 \mathrm{I}-300$ ETB & $99(26.9)$ & $12(19.0)$ & $0.269(0.062-1.169)$ & 0.08 \\
\hline$>300$ ETB & $71(19.3)$ & $24(38.1)$ & $\mathrm{I}$ & \\
\hline \multicolumn{5}{|c|}{ History of attempt to lose weight } \\
\hline Yes & $226(6 I .4)$ & $13(20.6)$ & $6.085(1.998-18.529)^{*}$ & 0.001 \\
\hline No & $142(38.6)$ & $50(79.4)$ & 1 & \\
\hline \multicolumn{5}{|c|}{ History of depression or anxiety } \\
\hline Yes & $314(85.3)$ & $26(4 \mid .3)$ & I $3.607(4.542-40.767)^{*}$ & $<0.001$ \\
\hline No & $54(\mid 4.7)$ & 37 (58.7) & 1 & \\
\hline \multicolumn{5}{|c|}{$\begin{array}{l}\text { Disruption of social networks, eg, } \\
\text { family, friends or people they love }\end{array}$} \\
\hline Yes & $260(70.7)$ & $26(4 I .3)$ & $3.218(1.261-8.212)^{*}$ & 0.014 \\
\hline No & $108(29.3)$ & $37(58.7)$ & $\mathrm{I}$ & \\
\hline
\end{tabular}

Notes: *Statistically significant variables, **I ETB is equivalent to 0.06 USD.

Abbreviations: $\mathrm{Cl}$, confidence interval; $\mathrm{ETB}$, Ethiopian Birr; OR, odds ratio.

history of disruption of social network (AOR $=3.218,95 \%$ CI [1.261-8.212], $P=0.014)$.

\section{Students' behavioral and gynecologic factors versus PD}

Table 4 demonstrates the result of logistic regression of behavioral and gynecologic factors versus PD. The risk of PD was $\sim 19$ times higher in students consuming more than four glasses of tea per day compared with students who did not consume tea at all (AOR $=18.938,95 \% \mathrm{CI}$ [2.190-163.730], $P=0.008$ ), whereas students who consume less than four glasses of tea per day had 0.093 times less risk for PD when compared to that of nonconsumers (AOR $=0.093$, 95\% CI [0.023-0.376], $P \leq 0.001)$. Concerning Coca-Cola or Pepsi consumption, the risk of PD was approximately seven times higher in students consuming one and more

Table 4 Behavioral and gynecologic factors versus primary dysmenorrhea

\begin{tabular}{|c|c|c|c|c|c|c|}
\hline \multirow[t]{2}{*}{ Variable } & \multicolumn{2}{|c|}{$\begin{array}{l}\text { Primary } \\
\text { dysmenorrhea, n (\%) }\end{array}$} & \multirow[t]{2}{*}{ Crude OR (95\% Cl) } & \multirow[t]{2}{*}{$\begin{array}{l}\text { Adjusted OR } \\
(95 \% \mathrm{Cl})\end{array}$} & \multicolumn{2}{|l|}{$P$-value } \\
\hline & Yes & No & & & Crude & Adjusted \\
\hline \multicolumn{7}{|l|}{ Tea consumption per day } \\
\hline Not at all & $38(10.3)$ & $14(22.2)$ & 1.00 & & & \\
\hline$<4$ glasses per day & $292(79.3)$ & $46(73.0)$ & 8.01 (3.49-18.39) & $0.09(0.02-0.38)^{*}$ & $<0.001$ & $<0.001$ \\
\hline$>4$ glasses per day & $38(10.3)$ & $3(4.8)$ & $15.56(3.82-63.33)$ & $18.94(2.19-163.73)^{*}$ & $<0.001$ & 0.008 \\
\hline \multicolumn{7}{|c|}{ Coca-Cola or Pepsi consumption per day } \\
\hline Not at all & $244(66.5)$ & $52(82.5)$ & 1.00 & & & \\
\hline One Coca-Cola per day & $124(33.7)$ & II (I7.5) & $2.40(1.21-4.77)$ & $6.79(1.88-24.47)^{*}$ & 0.012 & 0.003 \\
\hline \multicolumn{7}{|l|}{ Chocolate consumption per day } \\
\hline Not at all & $339(92.1)$ & $55(87.3)$ & 1.00 & & & \\
\hline Two bars of chocolate per day & $29(7.9)$ & $8(12.7)$ & $0.59(0.26-1.35)$ & $0.19(0.04-0.82)^{*}$ & 0.212 & 0.026 \\
\hline \multicolumn{7}{|l|}{ Parity } \\
\hline Nullipara & $337(91.6)$ & $35(55.6)$ & $8.7(4.69-16.14)$ & $47.32(11.04-202.86)^{*}$ & $<0.001$ & $<0.001$ \\
\hline Multipara & $31(8.4)$ & $28(44.4)$ & 1.00 & & & \\
\hline \multicolumn{7}{|l|}{ Family history of dysmenorrhea } \\
\hline Yes & $242(65.8)$ & $10(15.9)$ & 10.18 (5.01-20.69) & $27.23(8.03-92.35)^{*}$ & $<0.001$ & $<0.001$ \\
\hline No & $126(34.2)$ & $53(84.1)$ & 1.00 & & & \\
\hline
\end{tabular}

Note: *Statistically significant.

Abbreviations: $\mathrm{Cl}$, confidence interval; $\mathrm{OR}$, odds ratio. 
than one Coca-Cola or Pepsi per day compared with that of nonconsumers (AOR $=6.786,95 \%$ CI [1.881-24.476], $P=0.003)$. On the other hand, the risk of PD was found to be 0.186 times less in students who ate two or more chocolates per day compared with nonconsumers $(\mathrm{AOR}=0.186,95 \%$ CI [0.042-0.815], $P=0.026)$.

Concerning gynecologic factors, the risk of PD was 47 times higher in students who are nullipara compared with students who are multipara. The risk of PD in students who had a family history of dysmenorrhea was $\sim 27$ times higher than students with no prior family history.

\section{Discussion}

This study shows a high prevalence of PD (85.4\%), which is slightly higher than a study done in Dumlupinar University in Kutahya Health High School, Western Turkey (72.7\%); ${ }^{17}$ a study done in three medical colleges of India $(73.83 \%) ;{ }^{10} \mathrm{a}$ study conducted in Dabat and Kola Diba North West Ethiopia among secondary school adolescent students $(72 \%),{ }^{16}$ but more higher than a study done among Nigeria college students $(62.5 \%) ;{ }^{15}$ a study done in Turkish University $(55.5 \%) ;{ }^{10}$ and a study done among Mexican university students (64\%). ${ }^{11}$ A difference among these studies could be due to the dissimilarity in the selected groups of students, age variation, and the absence of universally accepted methods of defining PD because many studies use the definition of dysmenorrhea. The variations in sociocultural, ethnic, and lifestyle factors among university students could also be due to other pertinent reasons. But the prevalence of PD in this study was similar with a study done among Thai secondary school students in KhonKaen province which was $\sim 85 \%{ }^{12}$

The mean age of this study was 20.57 years, which is similar to a study done among Nigeria college students (21.1 years $)^{15}$ and students from Turkey University (21.47 years). ${ }^{6}$ This study shows the age at menarche was 14.96 years, which is concurrent with a study done among Nigeria college students (14.2 years $)^{15}$ but slightly higher than with a study done at Turkey University (13.08 years). ${ }^{6}$ The possible justification for this variation could be the difference of the study groups in socioeconomic status and the studies were carried out among different age groups.

This study shows that more than half of the female students $(56.9 \%)$ had moderate and severe types of PD, and $28.5 \%$ of the students had mild PD, which is slightly lower than that $(66.2 \%$ of students had moderate and severe dysmenorrhea) in another study. ${ }^{17}$ On the contrary, this study had a higher (38.1\% of moderate and $18.8 \%$ of severe) PD compared with a study, ${ }^{10}$ which revealed $30.37 \%$ with moderate dysmenorrhea and 6.32\% severe dysmenorrhea. The possible explanation for this variation could be the study participants' variance in menstrual pain characterization with differences of social, lifestyle, or cultural backgrounds among the students. Despite the observed percentage variation among studies, overall, PD in female students from different areas experience severe or moderate pain, which would impair their quality of life and have a negative effect on their academic performance.

Common symptoms mentioned in this study for PD were back pain or abdominal pain $(88.3 \%)$, mood change irritability and depression (57.8\%), menstrual irregularity (49.5\%), headache $(29.3 \%)$, pain at the groin $(27.2 \%)$, and sleeplessness $(17.3 \%)$, which are almost similar to a study done among Mexican university students, which indicated cramping lower abdominal pain (93\%), backache (43\%), irritability (50\%), depression (48\%), and headache (24\%), ${ }^{25}$ and a study done among Thai secondary school students in KhonKaen in which the major symptoms were mood change $(84.8 \%)$, headache $(37.5 \%)$, and backache $(63.7 \%)^{12}$

This study showed that among participants with PD, 88.3\% reported that $\mathrm{PD}$ had an effect on academic performance. Some of its effects were school absence (80\%), class absence $(56.3 \%)$, loss of class participation $(47.4 \%)$, loss of class concentration $(66.8 \%)$, limited sport participation $(37.8 \%)$, limited going out with friends $(31.7 \%)$, inability to do homework (21\%), and reduced test taking skill (15.4\%), which are somehow different with studies done among Hispanic female students in which there was a loss of class concentration (59\%), limited sport participation (51\%), loss of class participation ( $50 \%)$, homework (35\%), and test taking skill $(36 \%) .{ }^{13}$ The finding from this study is also different from a study done in KhonKaen, Thailand, ${ }^{12}$ which indicated poor class concentration $(73.9 \%)$, limited sport activity (59.8\%), and absence from school (18.2\%). In one of the effects, absence from school, a study done among Northwest Ethiopia secondary school adolescents revealed that $48.8 \%$ of students had suffered with PD and reported to be absent from school, which was also slightly lower compared with results of this study. This variation could be because of the difference in the operational definition of terms, severity of dysmenorrhea pain, and sociodemographic variables. Nevertheless, in all the studies, we can understand that PD interferes with their academic performance due to the intensity of the symptoms instead of the stigma related to it.

In addition, a finding from this study revealed that among students with PD, 47\% reported 1 day school absence, $23.4 \%$ 
reported 2 days school absence, and $5.7 \%$ of students reported 3 days school absence, which is comparable with a study done among Hispanic female adolescents with $46 \%$ with a half to 1 day of school absence, $36 \% 2$ to 3 days school absence, and $18 \%$ more than four school days' absence. ${ }^{13}$ Based on this finding, one can learn that PD is an important public health problem in school female attendees and brings a negative effect on their academic performance.

First year and second year students were mostly affected by PD than third and fourth year students though it was not statistically significant when adjusted. This might be because the first and second year female students are younger and they are in a new environment full of stress than the senior female students.

Regarding multivariate analyses, a history of an attempt to lose weight was an important risk factor for PD, which is comparable with findings from Dumlupinar University, ${ }^{17}$ and likewise a history of depression or anxiety and disruption of social networks with family, friends, or people they love was an important risk factor for PD. This is analogous with other studies. . $1,23,24^{2}$

A study done in Turkish university showed that PD was $\sim 1.5$ times higher in females with satisfactory stipend allowance, ${ }^{6}$ which is completely different from this study that shows PD is seven times higher in students with less monthly income than those with relatively large monthly income. From this study, one can imply that other factors, such as sociocultural and personal factors, had significant contributions to PD rather than individual's monthly income but it is suggested to have further research.

The prevalence of PD was higher among students who had a higher intake of tea and Coca-Cola or Pepsi, which is also represented in Turkish university students ${ }^{6}$ in whom dysmenorrhea was higher in women with an excessive sugar intake. The possible explanation for this relationship could be that vitamins and mineral absorption and metabolism are compromised by sugar intake. It then leads to muscle spasm, which can be manifested by menstrual pain.

In this study, those students with a family history of dysmenorrhea had a higher risk of developing PD. This finding is also confirmed by other studies from Turkish University ${ }^{6}$ and Dumlupinar University. ${ }^{17}$ To explain more, daughters of mothers with dysmenorrhea might experience and learn the same behaviors ${ }^{18}$ and evidently family history is basically associated with gynecologic problems. ${ }^{31}$

Parity was also found to be an important risk factor for PD in which being nullipara has more risk than being multipara. This could be explained by the presence of excessive release of prostaglandins by the endometrium and presence of large circulating prostaglandin hormones during menstruation with dysmenorrhea than women with no dysmenorrhea. This is again more frequent in nullipara than multipara. ${ }^{6}$

Many studies revealed that having a low BMI was an important risk factor for $\mathrm{PD}^{21,23,24}$ but in this study BMI was not an important risk factor for $\mathrm{PD}(P=0.732)$. The possible explanation for this could be many of the study participants had normal BMI $(80.5 \%)$ as well as the presence of difference in the measuring instrument among studies could also be valuable.

Other studies showed that early age at menarche was an important risk factor for PD, which is $<13$ years. ${ }^{21,23,24}$ But, in this study, students' age at menarche was not significantly associated with PD. Possibly, this discrepancy can be explained that in this study many of the respondents' age at menarche was above 13 years (82.6\%). Additionally, studies showed that having heavy menstrual blood flow had a significant association with PD; $;^{21,23,24}$ however, in this study, duration of menstruation was not significantly associated with PD $(P=0.116)$. The possible explanation might be due to the majority of the respondents $(68.2 \%)$ in this study having a normal duration of menstruation than the others.

\section{Limitations of the study}

This study included only one university, which may not be representative though students are enrolled from the whole regions of the country and show up as representative in terms of participants. It was also hard to compare results with local studies due to lack of research in the area. Besides, as the study design was cross-sectional, temporal relations could not be assessed. Lastly, from the participants' perspectives, there could be a recall bias and over-reporting of the condition as the students were asked for events within the last years prior to the study, such as a question about the age at menarche.

\section{Conclusion}

PD is prevalent in higher institutions and has a marked effect on students' academic performance. PD has a significant association with their educational level, monthly income, history of attempt to lose weight, depression or anxiety, and disruption of social network, tea drinking, Coca-Cola or Pepsi and chocolate intake, being nullipara, having menstrual irregularity, and having a family history of PD.

\section{Acknowledgments}

The authors are very thankful to Addis Ababa University for financial support. The authors also appreciate the support 
and cooperation offered by Debre Berhan University during data collection. Lastly, the study participants need to be acknowledged for their valuable information and involvement in the study.

\section{Author contributions}

All authors contributed toward data analysis, drafting and critically revising the paper, gave final approval of the version to be published, and agree to be accountable for all aspects of the work.

\section{Disclosure}

The authors report no conflicts of interest in this work.

\section{References}

1. Davis AR, Westhoff CL. Primary dysmenorrhea in adolescent girls and treatment with oral contraceptives. J Pediatr Adolesc Gynecol. 2001; 14(1):3-8.

2. Callejo J, Diaz J, Ruiz A, Garci RM. Effect of a low-dose oral contraceptive containing $20 \mu \mathrm{g}$ ethinylestradiol and $150 \mu \mathrm{g}$ desogestrel on dysmenorrhea. Contraception. 2003;68:183-188.

3. Cunningham AS, Muneyyirci-Delale $O$. The association between primary dysmenorrhea and hyperemesis gravidarum. Medical Hypotheses. 2009;73(1):90-91.

4. Li N, Liu H, Chen C, et al. CYP1A1 gene polymorphisms in modifying the association between passive smoking and primary dysmenorrhea. Ann Epidemiol. 2007;17(11):882-888.

5. Mannix KL. Menstrual-related pain conditions: dysmenorrhea and migraine. J Womens Health. 2008;17(5):879-891.

6. Ozerdogan N, Sayiner D, Ayranci U, Unsal A, Giray S. Prevalence and predictors of dysmenorrhea among students at a university in Turkey. Int J Gynaecol Obstet. 2009;107(1):39-43.

7. Ylikorkala O, Dawood MY. New concepts in dysmenorrhea. Am J Obstet Gynecol. 1978;130(7):833-847.

8. Dawood MY. Dysmenorrhea. J Reprod Med. 1985;30:154-167.

9. Klein JR, Litt IF. Epidemiology of adolescent dysmenorrhea. Pediatrics. 1981;68(5):661-664.

10. Singh A, Kiran D, Singh H, Nel B, Singh P, Tiwari P. Prevalence and severity of dysmenorrhea: a problem related to menstruation, among first and second year female medical students. Indian J Physiol Pharmacol. 2008;52(4):389-397.

11. Mario I, Ortiz IM. Primary dysmenorrhea among Mexican university students: prevalence, impact and treatment. Eur J Obstet Gynecol Reprod Biol. 2010;152(1):73-77.

12. Chongpensuklert Y, Kaewrudee S, Soontrapa S, Sakondhavut C. Dysmenorrhea in Thai Secondary School students in KhonKaen, Thailand. Thailand J Obstet Gynaecol. 2008;16(1):47-53.
13. Banikarim C, Chacko MR, Kelder SH. Prevalence and impact of dysmenorrhea on Hispanic female adolescents. Arch Pediatr Adolesc Med. 2000;154(12):1226-1229.

14. Balbi C, Musone R, Menditto A, et al. Influence of menstrual factors and dietary habits on menstrual pain in adolescence age. Eur J Obstet Gynecol Reprod Biol. 2000;91(2):143-148.

15. Esimie OA, Esan OGO. Awareness of menstrual abnormality amongst college students in urban area of Ile-Ife, Osun state, Nigeria; 2010. Available from: http://www.ijcm.org. Accessed March 17, 2016.

16. Zegeye DT, Megabiaw B, Mulu A. Age at menarche and the menstrual pattern of secondary school adolescents in northwest Ethiopia. BMC Womens Health. 2009;9:29.

17. Unsa A, Ayranci U, Tozun M, Arslan G, Calik E. Prevalence of dysmenorrhea and its effect on quality of life among a group of female university students. Ups J Med Sci. 2010;115(2):138-145.

18. Dorn LD, Negriff S, Huang B, et al. Menstrual symptoms in adolescent girls: association with smoking, depressive symptoms, and anxiety. Journal of Adolescent Health. 2009;44:237-243.

19. Juang CM, Yen MS, Twu NF, Horng HC, Yu HC, Chen CY. Impact of pregnancy on primary dysmenorrhea review. Int J Gynaecol Obstet. 2006; 92(3):221-227.

20. Dawood YM. Dysmenorrhea. Clin Obstet Gynecol. 1990;33(1):168-178.

21. French L. Dysmenorrhea in adolescents: diagnosis and treatment. Paediatr Drugs. 2008;10(1):1-7.

22. Burnett MA, Antao V, Black A, et al. Prevalence of primary dysmenorrhea in Canada. J Obstet Gynaecol Can. 2005;27(8):765-770.

23. Latthe P, Mignini L, Gray R, Hills R, Khan K. Factors predisposing women to chronic pelvic pain: systematic review. Br Med J. 2006; 332(7544):749-755.

24. Tonini G. Dysmenorrhea, endometriosis and premenstrual syndrome. Minerva Pediatrics. 2002;54:525-538.

25. Ortiz MI. Primary dysmenorrhea among Mexican university students: prevalence, impact and treatment. Eur J Obstet Gynecol Reprod Biol. 2010;152(1):73-77.

26. Strinic T, Bukovic D, Pavelic L, et al. Anthropological and clinical characteristics in adolescent women with dysmenorrhea. Coll Antropol. 2003;27(2):707-711.

27. Baranowski AP, Abrams P, Fall M. Urogenital Pain in Clinical Practice. New York: Information Healthcare USA, Inc; 2007.

28. Dawood MY. Nonsteroidal anti-inflammatory drugs and changing attitudes toward dysmenorrhea. Am J Med. 1988;84(5A):23-29.

29. Andersch B, Milsom I. An epidemiologic study of young women with dysmenorrhea. Am J Obstet Gynecol. 1982;144(6):655-660.

30. Wewers ME, Lowe NK. A critical review of visual analogue scales in the measurement of clinical phenomena. Res Nurs Health. 1990;13(4): 227-236.

31. Patel V, Tanksale V, Sahasrabhojanee M, Gupte S, Nevrekar P. The burden and determinants of dysmenorrhoea: a population-based survey of 2262 women in Goa, India. BJOG. 2006;113(4):453-463.
International Journal of Women's Health

\section{Publish your work in this journal}

The International Journal of Women's Health is an international, peerreviewed open-access journal publishing original research, reports, editorials, reviews and commentaries on all aspects of women's healthcare including gynecology, obstetrics, and breast cancer. The manuscript management system is completely online and includes

\section{Dovepress}

a very quick and fair peer-review system, which is all easy to use. Visit http://www.dovepress.com/testimonials.php to read real quotes from published authors. 